\title{
Desiccation tolerance in the Antarctic moss Sanionia uncinata
}

\author{
Marisol Pizarro, Rodrigo A. Contreras, Hans Köhler and Gustavo E. Zúñiga* (i)
}

\begin{abstract}
Background: One of the most extreme environments on our planet is the Maritime Antarctic territory, due to its lowwater availability, which restricts the development of plants. Sanionia uncinata Hedw. (Amblystegiaceae), the main colonizer of the Maritime Antarctic, has effective mechanisms to tolerate this environment. It has been described that the tolerance to desiccation is mediated by the hormone abscisic acid (ABA), antioxidants systems, accumulation of compatible solutes and proteins of the late embryogenesis abundant (LEA). However, to date, these mechanisms have not been described in S. uncinata. Therefore, in this work, we postulate that the tolerance to desiccation in the Antarctic moss S. uncinata is mediated by the accumulation of ABA, the osmolytes proline and glycine betaine, and dehydrins (an LEA class 11 proteins). To demonstrate our hypothesis, S. uncinata was subjected to desiccation for $24 \mathrm{~h}$ (loss in 95\% of water content), and the effects on its physiological, photosynthetic, antioxidant and biochemical parameters were determined.
\end{abstract}

Results: Our results showed an accumulation of ABA in response to water loss, and the activation of protective responses that involves an increment in levels of proline and glycine betaine, an increment in the activity of antioxidant enzymes such as SOD, CAT, APX and POD, and the accumulation of dehydrins proteins.

Conclusion: The results showed, suggest that $S$. uncinata is a desiccation-tolerant moss, property mediated by high cellular plasticity regulated by ABA.

Keywords: Antarctic mosses, ABA, Water stress, Desiccation tolerance, Maritime Antarctic

\section{Background}

Water availability is a limiting factor for any lifeform, but some plants have developed a mechanism that allows them to avoid or deal with water scarcity, especially those species that evolve during desiccation events $[1,2]$. Desiccation tolerance is defined as the ability to survive the decrease of the intracellular water content above 90 percent without irreversible damage [3, 4]. One of the largest groups of plants that can survive low water availability is bryophytes. This taxon belongs to the first lineage of land plants and most of them are desiccation tolerant [5]. Bryophytes are subdivided into mosses, liverworts, and hornworts, they have evolutive traits that give them

*Correspondence: gustavo.zuniga@usach.cl

Laboratorio de Fisiología y Biotecnología Vegetal, Departamento de Biología, Facultad de Química y Biología, and CEDENNA, Universidad de Santiago de Chile, Av. Libertador Bernardo O’Higgins 3363, Estación Central, Santiago, Chile an advantage over other species to colonize places with low water availability. These characteristics include; small size, radial growth, cell by cell water transport, external water transport, the presence of rhizoids to attach to rocks, wood and other surfaces [5].

Sanionia uncinata (Amblystegiaceae) is one of the most abundant mosses colonizing maritime Antarctica; in this region, plants can experience very harsh environmental conditions such as sub-zero temperatures, poor soils, strong winds, fluctuations in UVB and PAR radiation and water deficit [6].

In general, plants have the capacity to respond against water depletion using mechanisms that involve the accumulation of compatible solutes like sugars and amino acids. These serve as osmoprotectant compounds stabilizing enzymes and membranes [1], accumulation of LEA (late embryogenesis proteins) proteins, specially dehydrins have protective properties described in vitro

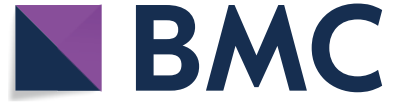

The Author(s) 2019. This article is distributed under the terms of the Creative Commons Attribution 4.0 International License (http://creativecommons.org/licenses/by/4.0/), which permits unrestricted use, distribution, and reproduction in any medium, provided you give appropriate credit to the original author(s) and the source, provide a link to the Creative Commons license, and indicate if changes were made. The Creative Commons Public Domain Dedication waiver (http://creativecommons.org/ publicdomain/zero/1.0/) applies to the data made available in this article, unless otherwise stated. 
when interacts with DNA, proteins, and membranes, also increases antioxidants molecules to control de oxidative burst and the potential damage by reactive oxygen species (ROS), these molecules can be enzymatic or non-enzymatic [7]. The enzymatic response involves the activity of SOD, a metalloenzyme that acts dismutating the superoxide ion $\left(\mathrm{O}_{2}{ }^{-}\right)$into hydrogen peroxide $\left(\mathrm{H}_{2} \mathrm{O}_{2}\right)$, this molecule can be transformed into $\mathrm{H}_{2} \mathrm{O}$ by ascorbate peroxidases (APX), catalases (CAT) or other types of peroxidases like POD [7].

Current studies show that many responses to dehydration in plants are regulated by abscisic acid, ABA, this phytohormone participates in stress signaling regulating the stomatal conductance, induces antioxidant enzymes [8], the accumulation of osmolytes [9] and induces late embryogenesis proteins [10]. There are novel studies that show the signaling pathway in model plants but there are no studies that show the participation of this hormone in the desiccation tolerance of Antarctic mosses.

Sanionia uncinata is one of the most abundant mosses that colonize Maritime Antarctic, belongs to the Amblystegiaceae family and there are no current studies that explain how these organisms can respond to the Antarctic ambient, especially to the drastic changes in water availability.

\section{Results}

In the conditions of drying, S. uncinata experienced a rapid loss of water during the first $6 \mathrm{~h}$ (84\% loss) (Fig. 1a). Then, between 6 and $24 \mathrm{~h}$, the loss of water from the moss was slower, reaching a minimum value of water in tissues of $5 \%$ after $24 \mathrm{~h}$ (Fig. 1a). Under these conditions S. uncinata showed a reduction in the volume of phyllids and cauloids, and a morphological change was triggered by desiccation were the photosynthetically active tissue, phyllids, was covered by the brown tissue of cauloids (Fig. 1b). With this result, kinetic desiccation (24 h) -rehydration $(36 \mathrm{~h})$ was performed.

The Antarctic moss shows a 95\% reduction of the water content at $24 \mathrm{~h}$ of dehydration, but the moss can recover almost $80 \%$ of their water content when is rehydrated (Fig. 2a). The physiological responses of the moss show that cellular respiration decrease when $S$. uncinata is desiccated but when the moss is rehydrated increase the respiration levels (Fig. 2b). The photosynthetic efficiency was affected negatively by desiccation at the beginning of desiccation the FV/FM value was 0.628 but at the end the decrease to 0.2 (Fig. 2c). S. uncinata submitted to desiccation shows an increase in ABA content, 3.5-fold, also we evaluate the content of ABA catabolites, but there is no increase in their levels (Fig. 3).

The homeostasis redox of $S$. uncinata was evaluated, the moss shows an slight increase in the ROS levels when was compared with the beginning of desiccation reaching a peak at the $12 \mathrm{~h}$ of treatment, but at the end of the treatment the moss presented a $81 \%$ of ROS levels reduction (Fig. 4a), this response is concomitant with an increase in the lipoperoxidation of membrane levels at $12 \mathrm{~h}$ of treatment, but at the end of the treatment returns to the basal levels (Fig. 4b), on the other hand, the antioxidant activity of SOD was negatively affected by desiccation decreasing a $47 \%$ their activity; the CAT activity increased 327\% when the moss was subjected to desiccation, APX increases a 90\% and POD a 218\% (Fig. 4c, d).

The osmolyte accumulation against desiccation show that Sanionia responds increasing the levels of proline
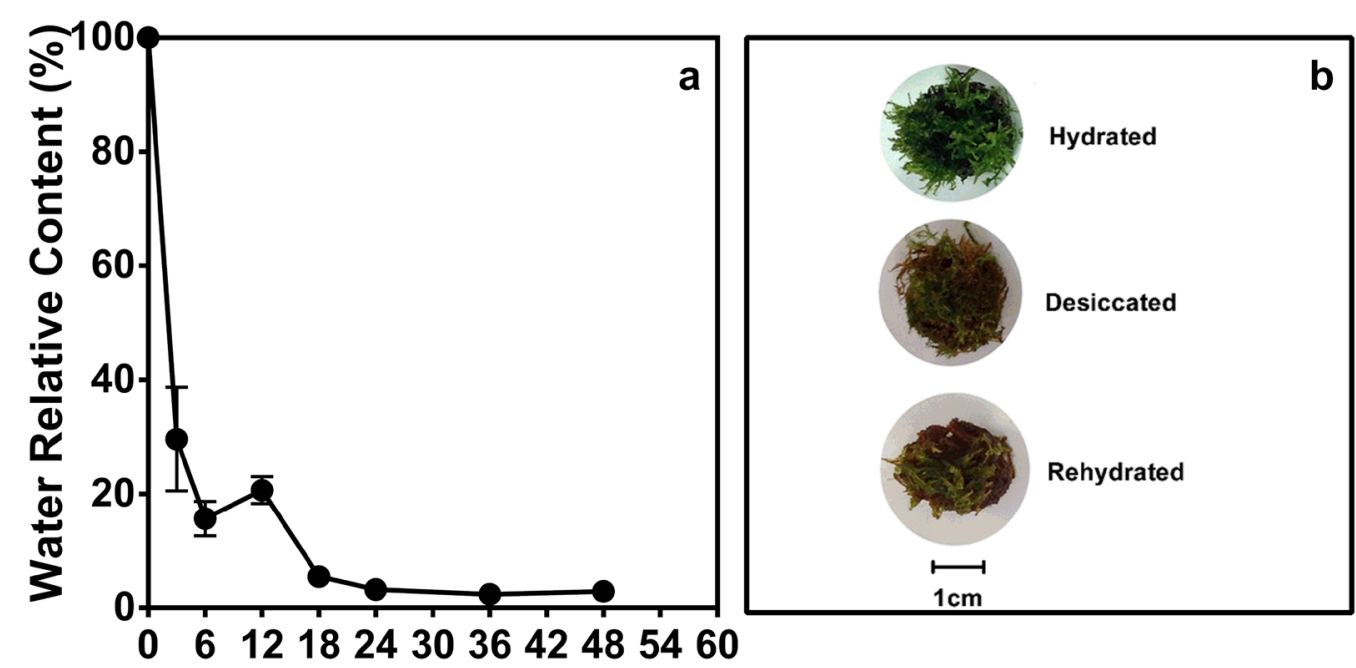

Fig. 1 Effect of desiccation in S. uncinata plants. Water relative content (a), morphology (b). The scale bar indicates a length of $1 \mathrm{~cm}$ 

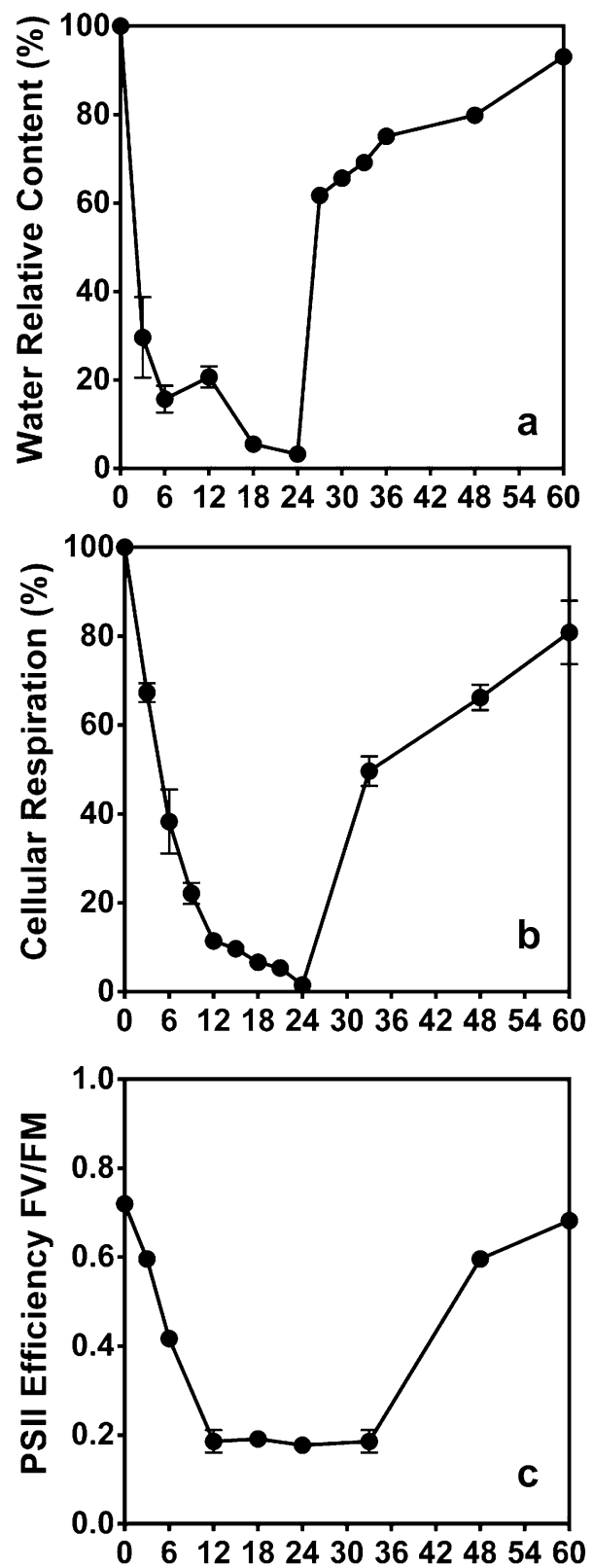

Fig. 2 Effect of desiccation on physiological parameters in $S$. uncinata plants. Water content percentage (a), cellular respiration percentage (b), photosynthetic efficiency (c). Each point represent means ( \pm standard error of the mean, $N=3$ ), $\mathrm{P}<0.05$

1565-fold and glycine betaine 367-fold (Fig. 5a, b), also the transcripts of genes that codified for the key enzymes in the biosynthesis of proline the pyrroline5-carboxylate synthase (P5CS) 7.4-fold and the gene betaine-aldehyde dehydrogenase 24-fold (BADH) involved in the glycine betaine biosynthesis increase when the moss is subject to desiccation (Fig. 5c, d).
The analysis of the transcript levels shows an increase of 14-fold, and the western blot analysis shows that $S$. uncinata (Fig. 6). The western blot analysis shows that the moss present 13 isoform under control conditions $(20,21,22,24,26,27,28,29,50,70,80,100,150 \mathrm{kDa})$ but when is desiccated present 14 isoforms, the $24 \mathrm{kDa}$ isoform is not present and two new forms 25 and $40 \mathrm{kDa}$ are present, also $S$. uncinata experiment an increment in the levels of the 19, 21, 50, 70, 80, 100 and $150 \mathrm{kDa}$ dehydrins (Fig. 7).

\section{Discussion}

The study of the behavior of S. uncinata to desiccation allows to determinate which responses are activated. $S$. uncinata shows a fast dehydration rate in $24 \mathrm{~h}$, reaching $5 \%$ of water content. The environmental water reduction induces an intracellular water reduction that affects the shape of the moss (Fig. 1) and the solvation shell of cytoskeletal proteins, vacuoles size and reduction on the membrane fluidity [4].

In S. uncinata the decrease of water content is related to an increase in ABA levels, these responses present to peaks, the first one is related to the release of the hormone from the $\mathrm{ABA}$ conjugates. $\mathrm{ABA}$ conjugates are the major reservoir of the inactive hormone; these mechanisms ensure rapid signaling when the molecules are hydrolyzed [11]. The second peak is related to the novo biosynthesis, these processes occur to a minor velocity because it implies transcription of the enzymes genes that are involved in the biosynthetic pathway [12]. ABA it is well known to participate in seed development, stomatal conductance and stress responses in vascular plants, but some studies show that ABA also can be present in non-vascular plants, the pretreatment confers desiccation tolerance to $P$. patens and $\mathrm{ABI} 3$ is the transcription factor that responds to this hormone, when de A, B, C ABI3 genes were deleted, the responsive genes were not upregulated [13]. In Syntrichia caninervis they observed upregulation in the AP2-ERF genes during desiccation [14]. Other studies show that ABA treatment in Atrichum undulatum increases the desiccation tolerance through the photosynthetic efficiency, increasing $F_{0}$ and the non-photochemical quenching of the moss [15] and this hormone also induces the accumulation of soluble sugars in P. patens [16], the last response was observed in S. uncinata revealing a possible control by this hormone.

When S. uncinata was submitted to desiccation, experimented a reduction in the metabolic activity, leading to a decrease in respiration and photosynthesis, but cellular respiration was less affected by desiccation at the beginning of the experiment, it has been reported that some plant can maintain their oxygen consumption rate until a $30 \%$ of water content, allowing to the plant to maintain 


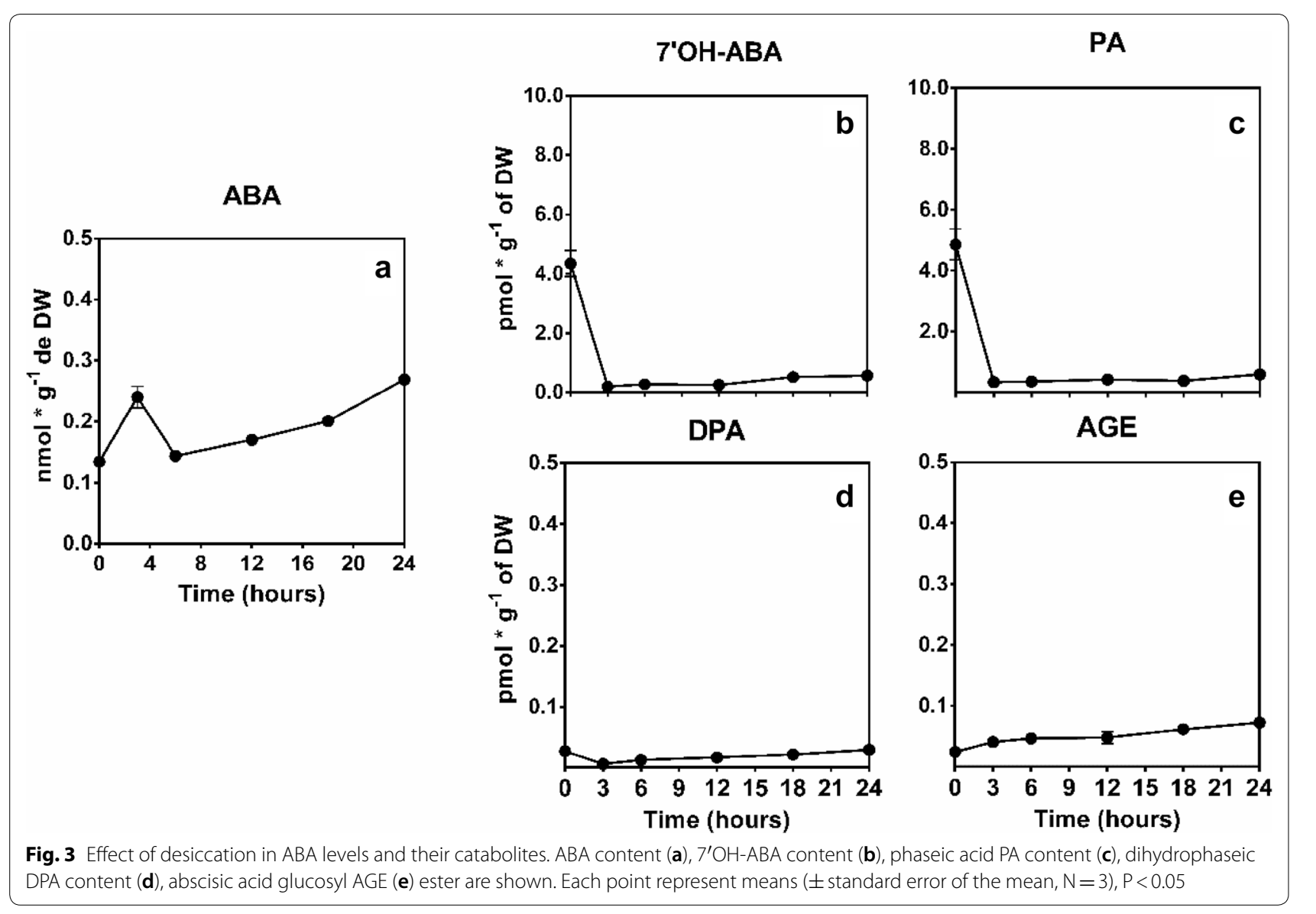

a basal energetic level to establish the responses against stress $[17,18]$. Photosynthesis was affected rapidly by desiccation, probably because the water is one of the substrates in the photochemical phase; also, the lack of water alters the structure of thylakoid membranes [3].

Photosynthetic efficiency it an indicator of the activity of PSII and the fundament is related to chlorophylls fluorescence when the system is working efficiently the energy is dissipated in the photochemical processes, but when stress is present, the energy is dissipated by nonphotochemical phenomena as heat liberation and chlorophyll fluorescence [19]. S. uncinata experienced mented a fast decrease in the PSII efficiency, but when the moss was rehydrated, fully recover the activity of PSII, these rapid recovery responses is related to the photosynthetic pigments, because the moss under desiccation no degraded the chlorophylls. The organisms that present this condition are known as poikilochlorophyllic species. The poikilochlorophyllic organisms maintain the chlorophylls and photosystems integrity avoiding the non-enzymatic degradation by photo-oxidative damage $[20,21]$, using the carotenoids and xanthophylls present in the reaction centers in the photosystems. These compounds protect against an excess of energy using the double conjugated bonds that allow them to capture the excess of energy and dissipate it, process known as nonphotochemical quenching [22].

Desiccation affects the fluidity and stability of organelle membranes, allowing the electron leak from the electron chain transport [1], that lead to the generation of reactive oxygen species, like singlet oxygen $\left({ }^{1} \mathrm{O}_{2}\right)$, superoxide ion $\left(\mathrm{O}_{2}^{-}\right)$, hydroxyl radical $(\mathrm{OH} \cdot)$ and peroxides, mainly the oxygen peroxide [7, 23]. Our results show that $S$. uncinata have an increase in ROS levels, but at the end of the experiment ROS return to basal levels, these are consistent with the grade of lipoperoxidation, the moss experiment a slight increase that was controlled at the $24 \mathrm{~h}$ of the desiccation, similar behavior was observed in the moss $F$. antipyretica under fast desiccation treatment [24], but they also show that a slow desiccation allows a better response by the moss, because enables the moss to engage the mechanisms against desiccation minimizing the damage.

In general, the control of the homeostasis redox is due to the action of antioxidant enzymes and non-enzymatic antioxidant like phenolic compounds, tocopherol, glutathione, 

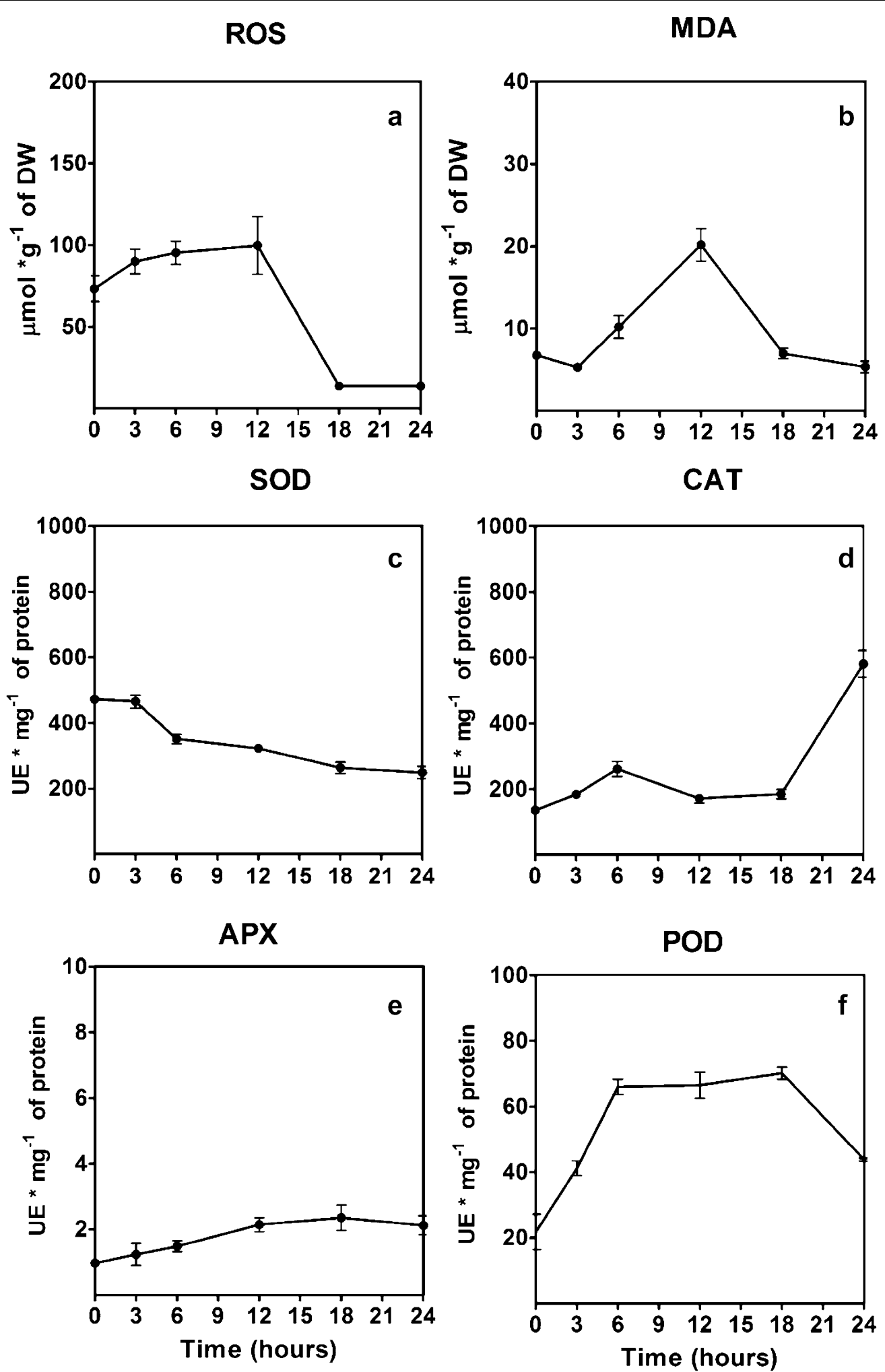

Fig. 4 Effect of desiccation in the antioxidant response of S. uncinata plants desiccated for $24 \mathrm{~h}$. The content of total ROS levels (a), malondialdehyde levels $(\mathbf{b})$, superoxide dismutase activity $(\mathbf{c})$, catalase activity $(\mathbf{d})$ ascorbate peroxidase activity (e), the total activity of peroxidases (f) is observed. Each point represent means ( \pm standard error of the mean, $N=3$ ), $\mathrm{P}<0.05$ 
Pro

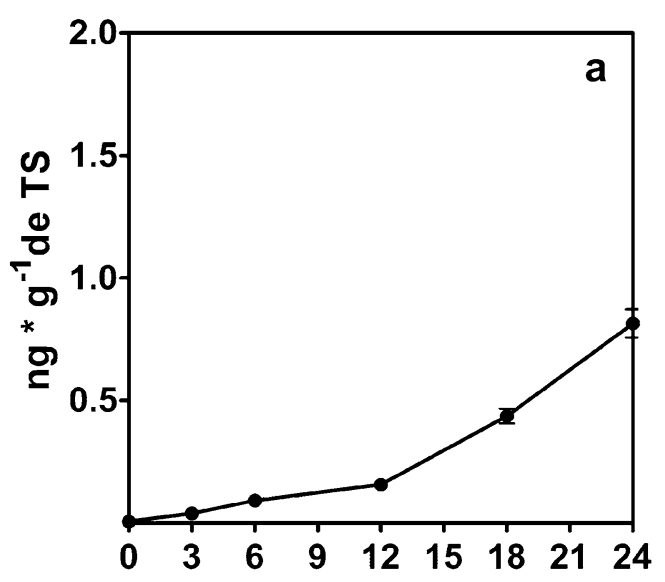

P5CS

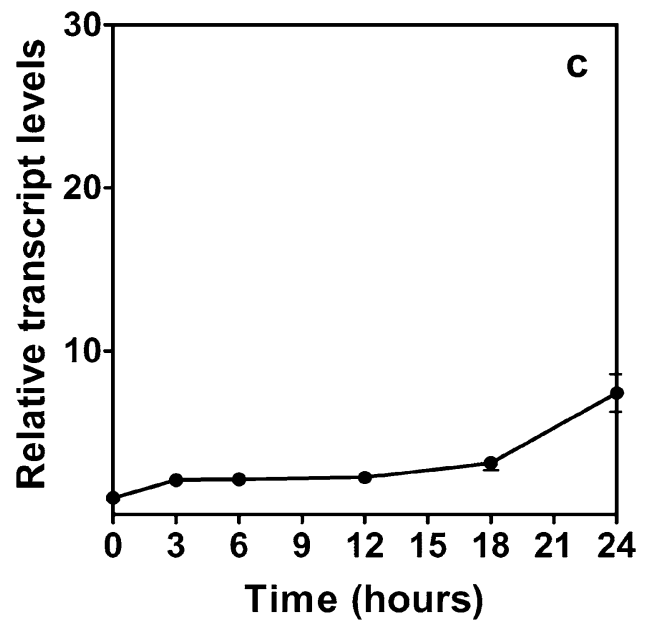

GB

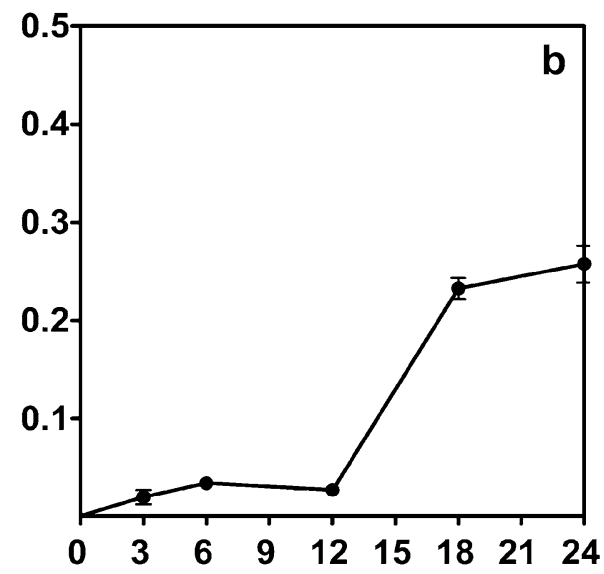

$B A D H$

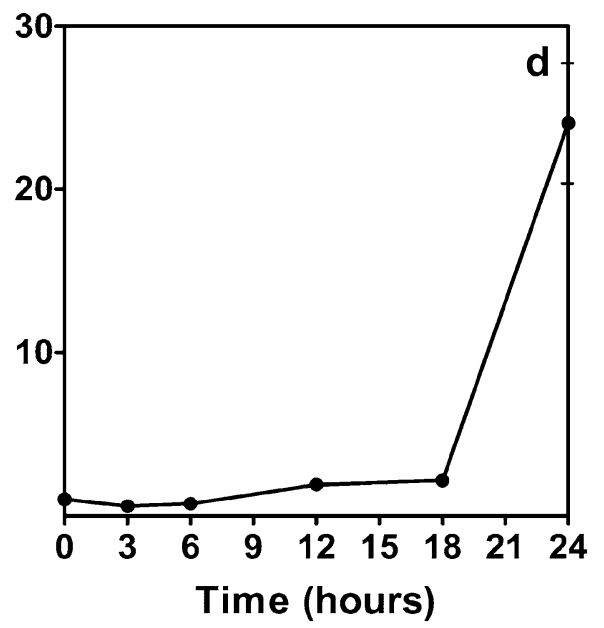

Fig. 5 Effect of desiccation in the osmolytes and transcript levels of P5CS and BADH genes in S. uncinata plants desiccated for 24 h. The content of proline $(\mathbf{a})$, glycine betaine content $(\mathbf{b})$, relative transcript levels of P5CS gene $(\mathbf{c})$, relative transcript levels of BADH gene $(\mathbf{d})$ are shown. Each point represent means ( \pm standard error of the mean, $N=3$ ), $P<0.05$

ascorbate among others [7]. We assay the activity of four antioxidant enzymes, superoxide dismutase (SOD), catalase (CAT), ascorbate peroxidase (APX) and type III peroxidases (POD). These enzymes we capable to control the ROS levels in $S$. uncinata under fast desiccation treatment. SOD acted at the beginning of the desiccation converting the superoxide radical in a less reactive molecule, and then the hydrogen peroxide was detoxified into the water by the action of CAT, APX, and POD where the most active enzyme was POD. S. uncinata respond to desiccation not only across the antioxidant responses, also accumulates compatible osmolytes that are highly sensitive to environmental stress [1], this mechanism is not only a preventive response also a tolerance response involves the water shell replacement of molecules inside the cell preventing the protein denaturation and membrane fusion [1, 25]. One of the characteristics of these compounds is that they not interfere with the metabolic activity of the cell and respond to the mechanic stress, loss of turgor and destabilization of membranes [1] also the transcripts related to the sugar machinery increase during dehydration and rehydration [26]. The moss accumulates proline and glycine- betaine, these compounds immobilize the cytoplasm forming a glassy matrix that protect the biomolecules preventing the solvation shell removal, and the decrease in ionic strength [27]. These responses where observed in the moss Atrichum undulatum under moderated desiccation. The increasing levels of these osmolytes is due to 


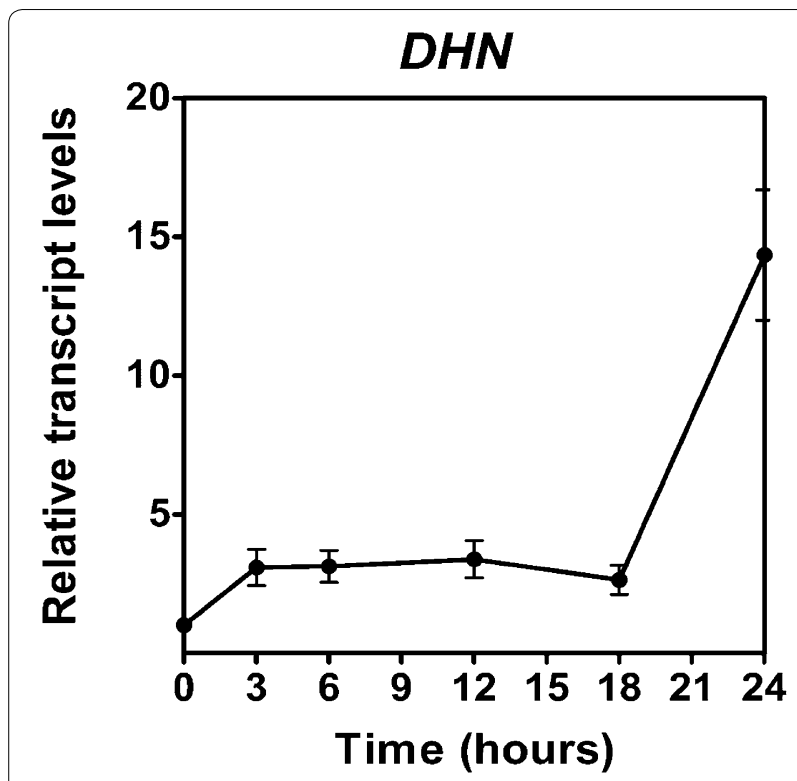

Fig. 6 Effect of desiccation in the dehydrins transcript levels of S. uncinata plants desiccated for $24 \mathrm{~h}$. Each point represent means ( \pm standard error of the mean, $N=3$ ), $P<0.05$

biosynthesis the novo, because not significant increase was observed until the $9 \mathrm{~h}$ of desiccation for proline ant $12 \mathrm{~h}$ to glycine-betaine, the biosynthesis occurs first because de transcripts of the P5CS were induced since the 3rd hour of treatment while the transcript of $\mathrm{BADH}$ was induced since the 9th hour of treatment and the osmolyte increase was discrete when is compared to the increase of proline. Proline is a relevant molecule not only for the osmolyte action but also has the capacity to chelate metals, stabilizes molecules like lipids and proteins and acts like an antioxidant and hydrotrope $[28,29]$. Glycine-betaine contributes to the osmotic adjustment and stabilizes biomolecules, protecting the membranes of thylakoids and RUBISCO $[28,30]$. S. uncinata presents high and low molecular weight dehydrins. Dehydrins can interact with all the biomolecules of the cell, like proteins, lipids and nucleic acids, are widely distributed in the cell, including the nucleus, chloroplasts, mitochondrion, and cytoplasm [27]. Dehydrins are part of the primary response against desiccation because of conferee preferential hydration of molecules when the intracellular water potential decrease [1]. Dehydrins also can sequester ions and due to their hydrophilic properties are able to form hydrocolloid that stabilizes the cytoplasm [31]. The moss $B$. argenteum shows a plastic response under desiccation that involves the activation of the transcription and translation machinery, cytoskeleton, sugar metabolism and secondary metabolism [32]. Also, studies of the proteome of the moss $P$. patens under a desiccation treatment shows an increase in group 2 of LEA proteins, dehydrins, and heat shock proteins [33]. A similar response

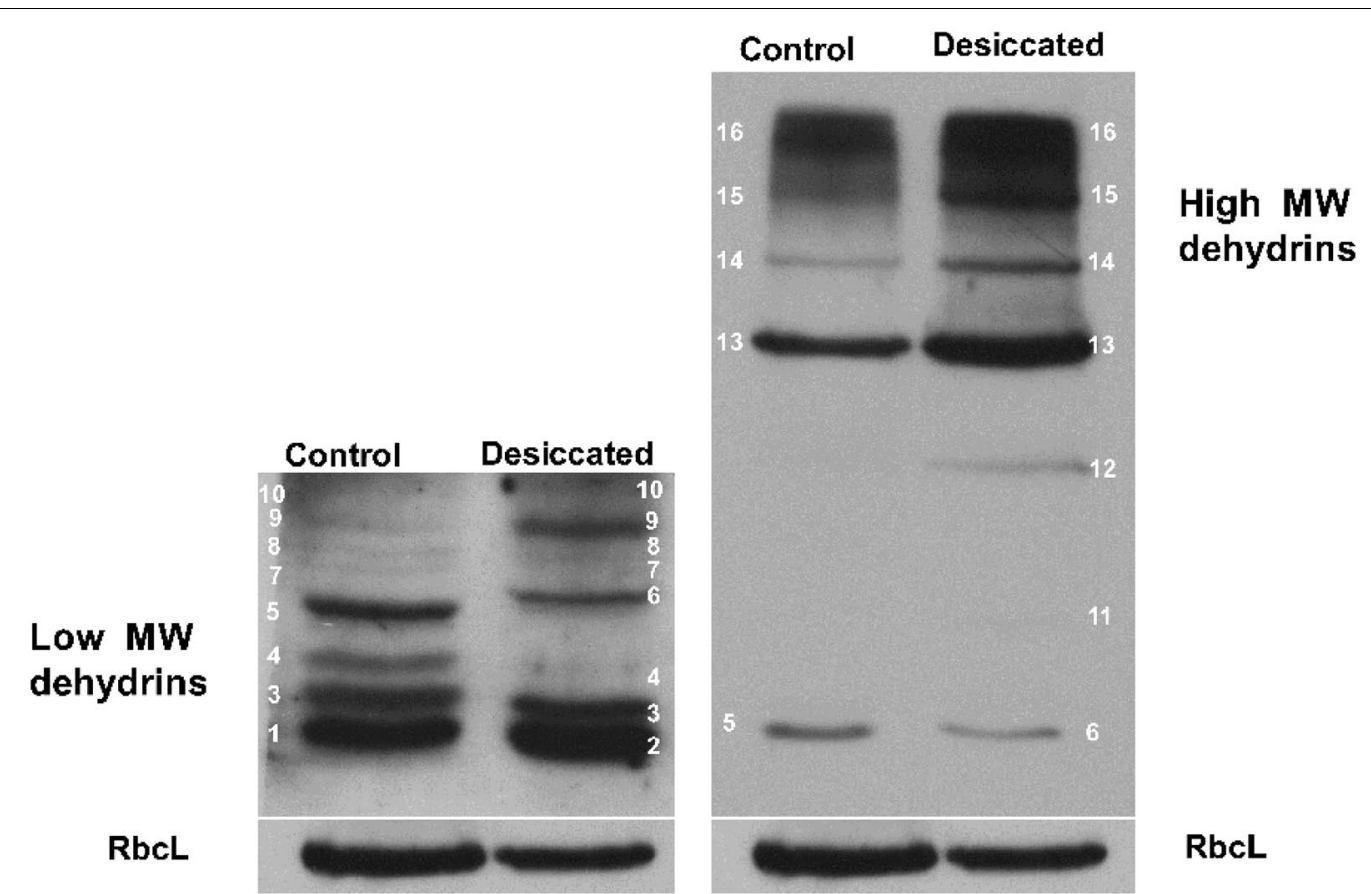

Fig. 7 Western blot of the isoforms of dehydrins of S. uncinata desiccated for $24 \mathrm{~h}$. (1) $20 \mathrm{kDa}$, (2) $19 \mathrm{kDa}$, (3) $21 \mathrm{kDa}$, (4) $22 \mathrm{kDa}$, (5) $24 \mathrm{kDa}$, (6) $25 \mathrm{kDa}$, (7) $26 \mathrm{kDa}$, (8) $27 \mathrm{kDa}$, (9) $28 \mathrm{kDa}$, (10) $29 \mathrm{kDa}$, (11) $40 \mathrm{kDa}$, (12) $50 \mathrm{kDa}$, (13) $70 \mathrm{kDa}$, (14) $80 \mathrm{kDa}$, (15) $100 \mathrm{kDa}$, (16) $150 \mathrm{kDa}$, RbcL $55 \mathrm{kDa}$ 
was found in S. uncinata. Under control conditions present 13 isoforms $(20,21,22,24,26,27,28,29,50,70,80,100$, $150 \mathrm{kDa}$ ) but when is desiccated present 14 isoforms, the $24 \mathrm{kDa}$ isoform is not present and two new forms 25 and $40 \mathrm{kDa}$ accumulates, also $S$. uncinata experiment an increment in the levels of the 19, 21, 50, 70, 80, 100 and $150 \mathrm{kDa}$ dehydrins, showing a dynamic response, and probably the pattern would change during rehydration. The responses of mosses against dehydration are dynamic [32] but they possess some constitutive mechanisms of protection that allow mosses to respond against desiccation despite the rate of water loss and according to our findings S. uncinata have the same behavior.

\section{Conclusion}

Sanionia uncinata experienced a rapid loss of water, during the drying treatment. S. uncinata can tolerate desiccation due to the establishment of mechanisms that involves the control of the homeostasis redox, the osmotic adjustment and the accumulation of molecules like osmolytes and dehydrins that stabilizes the cell and their components, and the responses observed offers new insights in the Antarctic moss responses to water scarcity during climate change.

\section{Materials and methods}

\section{Plant material}

Plants of S. uncinata were collected from soil on King George Island, Maritime Antarctic and, the moss was cleaned and rinsed with water, then was cultured with liquid BCD media at $10 \pm 2{ }^{\circ} \mathrm{C}$, and $16 \mathrm{~h}$ of light and $8 \mathrm{~h}$ of darkness for 3 months prior desiccation treatment [34, 35]. Before the desiccation treatment, the moss was rinsed with water and maintain fully hydrated for 30 days. The fully hydrated state was considered as the $100 \%$ of relative water content of the moss and $3 \mathrm{~cm}$ shoots were placed in culture microplates ( 12 wells) inside a desiccator with silica gel bags, the silica treatment represents fast desiccation rate; we consider the moss desiccated when the mass was constant in the time, approximately a loss in $95 \%$ of original mass. The samples were collected every $3 \mathrm{~h}$ for $24 \mathrm{~h}$ and stored at $-80^{\circ} \mathrm{C}$ before processing.

\section{Relative water content}

Fresh moss tissue was collected every $3 \mathrm{~h}$ measured and the weight was determined immediately, then the tissue was dried using an oven at $65^{\circ} \mathrm{C}$ for at least $48 \mathrm{~h}$ until the weight was constant $[36,37]$. The percentage of water was calculated using Eq. (1).

$$
\frac{\text { Initial fresh weight }- \text { final fresh weight }}{\text { Initial fresh weight }} \times 100 \text {. }
$$

\section{Photosynthetic efficiency of photosystem II (PSII)}

A photosynthetic efficiency analyzer (FMS II, Hansatech, Norfolk, UK) was used to measure photosynthetic efficiency through the determination of the variable and maximum fluorescence of PSII. The moss was dark adapted for 15 min covering the system with aluminum foil. The optic fiber was placed on the tip of the mosses using an adapter (provided by the manufacturer), ensuring that every measuring was made at the same distance. Results are expressed as $\mathrm{F}_{\mathrm{v}} / \mathrm{F}_{\mathrm{m}}$ (maximum efficiency of PSII).

\section{Photosynthetic pigments (Chl-a/b)}

The total content of Chl- $a$ and Chl- $b$ was determined using fresh tissue $(100 \mathrm{mg})$ that was ground to a powder using liquid nitrogen, mortar and pestle before extraction in ethanol $(1 \mathrm{~mL})$. The extract was centrifuged at $10,000 \mathrm{rpm}$ for $10 \mathrm{~min}$ at $4{ }^{\circ} \mathrm{C}$ and the absorbance of the supernatant at 470, 649 and $665 \mathrm{~nm}$ was measured [21]. Chlorophyll concentration was determined using Eqs. (2) and (3). Carotenoids concentration was determined using Eq. (4)

$$
\begin{aligned}
& \text { Chl- } a(\mu \mathrm{g} / \mathrm{mL})=13.36 \cdot \mathrm{A}_{665}-5.19 \cdot \mathrm{A}_{649} \\
& \text { Chl- } b(\mu \mathrm{g} / \mathrm{mL})=27.43 \cdot \mathrm{A}_{649}-8.12 \cdot \mathrm{A}_{665} \\
& \mathrm{C}_{\mathrm{x}+\mathrm{c}}(\mu \mathrm{g} / \mathrm{mL})=\left(1000 \cdot \mathrm{A}_{470}-2.13 \mathrm{C}_{\mathrm{a}}-97.63 \mathrm{C}_{\mathrm{b}}\right) / 209 .
\end{aligned}
$$

\section{Total reactive oxygen species (ROS)}

Total ROS was analyzed using fluorometric quantitation of dichlorodihydrofluorescein-diacetate (DCDHFDA) method. Fresh plant tissue $(100 \mathrm{mg})$ was incubated in $1 \mathrm{~mL}$ of $10 \mu \mathrm{M}$ of DCDHF-DA prepared in Tris- $\mathrm{HCl}$ (50 mM, pH 8.0) for $1 \mathrm{~h}$ at room temperature. Tissue was then rinsed with EDTA $50 \mathrm{mM}$ to remove the excess of DCDHF-DA, the tissue was ground to a fine powder and extracted in $1 \mathrm{~mL}$ of Tris- $\mathrm{HCl}(50 \mathrm{mM}, \mathrm{pH} 8.0)$. The supernatant obtained after centrifugation at $10.000 \mathrm{rpm}$ for $5 \mathrm{~min}$ (Heraeus Biofuge fresco, Kendro Laboratory, Hong Kong), fluorescence intensity was measured using a $488 \mathrm{~nm}$ wavelength for excitation and $535 \mathrm{~nm}$ [38].

\section{Membrane peroxidation}

Fresh tissue (100 mg) was ground to a powder and suspended in $1 \mathrm{~mL}$ of $1 \%$ of trichloroacetic acid (TCA), then was centrifuged at $10,000 \mathrm{rpm}$ for $5 \mathrm{~min}$. $250 \mu \mathrm{L}$ of the supernatant was added to $750 \mu \mathrm{L}$ of $0.5 \%$ of thiobarbituric acid in 20\% and the mixture was boiled for $15 \mathrm{~min}$, after this procedure the mixture was cooled to room temperature and the adduct formed by TBAmalondialdehyde (MDA) was quantified at $532 \mathrm{~nm}$ using $\sum=155 \mathrm{mM}^{-1} \mathrm{~cm}^{-1}$ [39]. 


\section{Enzymes extraction}

Fresh tissue (100 mg) was ground to a fine powder and extracted in $1 \mathrm{~mL}$ of potassium phosphate buffer (50 mM, pH 7.5). The mixture was centrifuged at $10,000 \mathrm{rpm}$ for $10 \mathrm{~min}$ at $4{ }^{\circ} \mathrm{C}$. The supernatant was recovered, and the concentration of the soluble proteins was determined using Bradford method [40] using bovine serum albumin (BSA) standard curve.

\section{Superoxide dismutase (SOD) activity (EC 1.15.1.1)}

A reaction mixture was prepared using $600 \mu \mathrm{L}$ of potassium phosphate buffer $(50 \mathrm{mM}, \mathrm{pH} 7.5), 10 \mu \mathrm{L}$ of $10 \mathrm{mM}$ EDTA, $100 \mu \mathrm{L}$ of $130 \mathrm{mM}$ methionine, $10 \mu \mathrm{L}$ of $2 \mathrm{mM}$ riboflavin, $200 \mu \mathrm{L}$ of $3 \mathrm{mM}$ of nitroblue tetrazolium in $70 \%$ dimethylformamide and $100 \mu \mathrm{L}$ of protein extract. The mixture was incubated under white light for $15 \mathrm{~min}$ at room temperature (a blank was kept in the dark). Absorbance was determined at $560 \mathrm{~nm}$ (spectrophotometer Espectr BID1, Agilent 8453, Santa Clara, USA) and expressed according to the capacity to inhibit $50 \%$ of photochemical reduction of NBT (50\% of the photochemical reduction of NBT equals 1EU) [41].

\section{Ascorbate peroxidase (APX) activity (EC 1.11.1.11)}

A reaction mixture that contained $935 \mu \mathrm{L}$ of potassium phosphate buffer $(50 \mathrm{mM}, \mathrm{pH} 7.5), 20 \mu \mathrm{L}$ of protein extract, $5 \mu \mathrm{L}$ of $100 \mathrm{vol}$. hydrogen peroxide and $40 \mu \mathrm{L}$ of $10 \mathrm{mM}$ sodium ascorbate were prepared. Absorbance was recorded at $290 \mathrm{~nm}$ for $1 \mathrm{~min}$ (spectrophotometer Espectr BID1, Agilent 8453, Santa Clara, USA), the activity was expressed according to the ascorbate consumption using molar extinction of ascorbate, $\sum=2.8 \mathrm{mM}^{-1} \mathrm{~cm}^{-1}[42]$.

\section{Peroxidase (POD) activity (EC 1.11.1.7)}

A reaction mixture that contained $980 \mu \mathrm{L}$ of sodium phosphate buffer $(50 \mathrm{mM}, \mathrm{pH} 7.5), 10 \mu \mathrm{L}$ of protein extract, $5 \mu \mathrm{L}$ of $100 \mathrm{vol}$. hydrogen peroxide and $5 \mu \mathrm{L}$ of guaiacol were prepared. Absorbance was recorded at $470 \mathrm{~nm}$ for $1 \mathrm{~min}$ (spectrophotometer Espectr BID1, Agilent 8453, Santa Clara, USA). POD activity was expressed in terms of tetrahydroguaiacol (THG) formation using molar extinction of THG, $\sum=26.6 \mathrm{mM}^{-1} \mathrm{~cm}^{-1}[43]$.

\section{Catalase (CAT) activity (EC 1.11.1.6)}

A reaction mixture that contained $975 \mu \mathrm{L}$ of potassium phosphate buffer $(50 \mathrm{mM}, \mathrm{pH} 7.5), 20 \mu \mathrm{L}$ of protein extract and $5 \mu \mathrm{L}$ of $100 \mathrm{vol}$. hydrogen peroxide was prepared. Absorbance was measured at $240 \mathrm{~nm}$ for 1 min (spectrophotometer Espectr BID1, Agilent 8453, Santa Clara, USA). CAT activity was expressed in terms of hydrogen peroxide consumption using the molar extinction of hydrogen peroxide, $\sum=39.4 \mathrm{mM}^{-1} \mathrm{~cm}^{-1}$ [42].

\section{ABA content}

Fresh tissue $(100 \mathrm{mg})$ was ground to a fine powder with liquid nitrogen and extracted in $1 \mathrm{~mL}$ of methanol: formic acid: water 15:4:1. The mixture was centrifuged at $10,000 \mathrm{rpm}$ for $10 \mathrm{~min}$ at $4{ }^{\circ} \mathrm{C}$. The supernatant was recovered and filtered $(0.22 \mu \mathrm{m})$. A volume of $20 \mu \mathrm{L}$ of the extract was injected in a rheodyne valve into an HPLCESI-MS/MS system (Agilent LC-MS/MS 1200s-6410, Agilent Technologies, Santa Clara, CA, USA) equipped with a C18-reversed-phase column $(150 \times 4.6 \mathrm{~mm}, 5 \mu \mathrm{m}$, XDB-C18, Agilent Technologies, Santa Clara, USA), the mobile phase consists in a solution of $0.1 \%$ formic acid, the running was set at a flow rate of $0.3 \mathrm{~mL} / \mathrm{min}$ at room temperature. The detector was set in MRM mode (multiple reaction monitoring) at $-4500 \mathrm{~V}, 25 \mathrm{psi}$, and a $10 \mathrm{~mL} / \mathrm{min}$ flow rate of nitrogen. ABA $(263 \rightarrow 153 \mathrm{~m} / \mathrm{z})$ was used as standard (Sigma-Aldrich, MO, USA) and d6-ABA (269 $\rightarrow$ 159, Olchemim Ltd., Czech Republic) as an internal standard.

\section{Proline and glycine betaine content}

A volume of $200 \mu \mathrm{L}$ of enzyme extraction was filtered and $20 \mu \mathrm{L}$ was injected in a rheodyne valve into an HPLCESI-MS/MS system (Agilent LC-MS/MS 1200s-6410, Agilent Technologies, Santa Clara, CA, USA) equipped with an Astec Chirobiotic ${ }^{\mathrm{TM}}$ column $(150 \times 21 \mathrm{~mm}, 5 \mu \mathrm{m}$ pore size), the mobile phase consisted of a mixture of $0.1 \%$ of formic acid (A) and acetonitrile (B) 95.5:0.5 respectively, the flow rate was $0.5 \mathrm{~mL} / \mathrm{min}$. The detector was set in MRM mode (multiple reaction monitoring) at $4000 \mathrm{~V}, 35 \mathrm{psi}$, and a $9 \mathrm{~mL} / \mathrm{min}$ flow rate of nitrogen. Proline $(116 \rightarrow 70 \mathrm{~m} / \mathrm{z})$, Gly-betaine $(235 \rightarrow 118 \mathrm{~m} / \mathrm{z})$ and were used as standards (Sigma-Aldrich, MO, USA).

\section{Soluble sugar content}

Fresh tissue $(100 \mathrm{mg})$ was ground to a fine powder with liquid nitrogen and extracted in $1 \mathrm{~mL}$ of $85 \%$ ethanol. The extract was centrifuged at $10,000 \mathrm{rpm}$ for $10 \mathrm{~min}$ at $4{ }^{\circ} \mathrm{C}$. The supernatant was recovered and filtered $(0.45 \mu \mathrm{m})$. A volume of $20 \mu \mathrm{L}$ of the extract was injected in a rheodyne valve into an HPLC-RID system (Agilent 1100, Agilent Technologies, Santa Clara, CA, USA) equipped with a Sugar Pak I column $300 \mathrm{~mm} \times 6.5 \mathrm{~mm}$ (Waters, Waters Corp., Massachusetts, USA), the mobile phase consisted in a preboiled solution of Calcium EDTA $50 \mathrm{mg} / \mathrm{L}$ and the running was set to a flow rate of $0.35 \mathrm{~mL} / \mathrm{min}$ at room temperature. The refractive index detector was set at $55{ }^{\circ} \mathrm{C}$ and D-glucose, D-fructose, D-galactose, galactinol, 
Table 1 Primer set and temperature of melting for each gene (Tm)

\begin{tabular}{lll}
\hline Gene & Primers set & Tm $\left({ }^{\circ} \mathbf{C}\right)$ \\
\hline dhnA & AAACTCAGACGCGAGAGTCG & 60 \\
gols & TAAGGAGCGGGAATGTTCG & \\
& GTCCATTATTGTGCAGCGGG & 60 \\
P5CS & TGGGGTTGGACACATACAC & \\
& CTGCTGTTGTCACTCGGTCT & 60 \\
BADH & CCAACCCTCGACTTGTCTCC & \\
rrna18S & ATGAGCATCCCAATTCCCCA & 60 \\
& ATCGAGCGGTTTCCACAGT & \\
& CTTAGCAGAACGACCAGCGA & 60 \\
& TCTTCATCGATGCGAGAGCC &
\end{tabular}

sucrose, raffinose, stachyose and verbascose were used as standards (Sigma-Aldrich, St. Louis, USA).

\section{Dehydrins Western Blotting}

Protein extraction was prepared according to the protocol described above. The supernatant was collected and a volume of cooled acetone $\left(-20{ }^{\circ} \mathrm{C}\right)$ was added to the sample an incubated for $1 \mathrm{~h}$ at $-20^{\circ} \mathrm{C}$, the extract was centrifuged at $10,000 \mathrm{rpm}$ for $10 \mathrm{~min}$ at $4{ }^{\circ} \mathrm{C}$. The pellet was resuspended in phosphate buffer (50 Mm, pH 8.0), proteins were standardized by Bradford and a volume of $15 \mu \mathrm{L}$ was injected into the electrophoresis pocket. A broad range of protein molecular weight was used as a marker. Electrophoresis was performed for $2 \mathrm{~h}$ at $120 \mathrm{~V}$. The product was transferred to a nitrocellulose membrane (Merck Millipore Ltda, Tullagreen, USA) using a $300 \mathrm{~A}$ for $1 \mathrm{~h}$. The membrane was incubated for $1 \mathrm{~h}$ with $5 \%$ of fat free milk prepared in TTBS, the membrane was rinsed 3 times with TTBS and were incubated for $1 \mathrm{~h}$ at room temperature with the primary antibody anti-DHN 1:1000 prepared in 3\% of fat free milk in TTBS (Agrisera, Sweden) o were incubated also for $1 \mathrm{~h}$ with the primary antibody anti-RbcL 1:20,000, after the incubation the membrane was rinsed for 15, 10, 5 min with TTBS and the membranes were incubated with the secondary antibody anti-Rabbit IgG HRP conjugated (Agrisera, Sweden) de 1:10,000, after antibody treatment, the membranes were incubated for $3 \mathrm{~min}$ with Luminata Forte substrate (Merck, Tullagreen, USA) and the chemiluminescence were detected with $\mathrm{x}$-ray films (Fujifilm).

\section{Analysis of dhnA, gols, badh, p5cs and rrna $18 \mathrm{~S}$ gene transcript levels}

Total RNA was extracted per the manufacturer instructions described in the ISOLATE II RNA plant kit (Bioline reagents Ltda, London, United Kingdom), the purity was determined using the nanoquant assay (Infinite M200pro, Tecan, Sweden). The transcript quantification was assayed using the one step Brilliant II SYBR Green QRT-PCR1 master mix (Agilent Genomics, Santa Clara, USA). The primers set are described in Table 1.

\section{Abbreviations}

LEA: late embryogenesis proteins; ROS: reactive oxygen species; SOD: superoxide dismutase; APX: ascorbate peroxidase; CAT: catalase; POD: type III peroxidases; ABA: abscisic acid; PSII: photosystem II; Fv: variable fluorescence; Fm: maximum fluorescence; Chl- $a$ : chlorophyll $a$; Chl- $b$ : chlorophyll $b ; C_{x+c}$ : carotenoids; EDTA: ethylenediaminetetraacetic acid; DCDHF-DA: dichlorodihydrofluorescein-diacetate; TCA: trichloroacetic acid; TBA: thiobarbituric acid; MDA: malondialdehyde; BSA: bovine serum albumin; NBT: nitroblue tetrazolium; THG: tetrahydroguaiacol; MRM: multiple reaction monitoring.

\section{Acknowledgements}

Thanks to the Ph.D. program in Biotechnology at the University of Santiago of Chile, the training program of advanced human capital of the National Commission for Scientific and Technological Research of Chile (CONICYT) and the Chilean Antarctic Institute (INACH).

\section{Authors' contributions}

Experiments were conceived by MP, RC, HK and GEZ. MP and GEZ collected the moss samples, identified these samples to species. MP, set-up the greening laboratory experiment and recorded initial measurements and was the major contributor in writing the manuscript. MP, RC and HK; performed the compound extractions and analysis of all data. All authors read and approved the final manuscript.

\section{Funding}

Funding support was provided by National Commission for Scientific and Technological Research of Chile (CONICYT, Basal Program for Centers of Excellence, Grant FB0807 (EDENNA), FONDECYT (1140189 GEZ) and Chilean Antarctic Institute (INACH, RT_14-17 GEZ).

Availability of data and materials

All data generated or analyzed during this study are included in this published article.

Ethics approval and consent to participate

Not applicable.

Consent for publication

Not applicable.

\section{Competing interests}

The authors declare that they have no competing interests.

Received: 13 November 2017 Accepted: 6 August 2019

Published online: 21 August 2019

\section{References}

1. Hoekstra FA, Golovina EA, Tetteroo FA, Wolkers WF. Induction of desiccation tolerance in plant somatic embryos: how exclusive is the protective role of sugars? Cryobiology. 2001;43(2):140-50. https://doi.org/10.1006/ cryo.2001.2358.

2. Alpert P. The limits and frontiers of desiccation-tolerant life. Integr Comp Biol. 2005;45(5):685-95. https://doi.org/10.1093/icb/45.5.685.

3. Farrant JM. A comparison of mechanisms of desiccation tolerance among three angiosperm resurrection plant species. Plant Ecol. 2000;151(1):29_ 39. https://doi.org/10.1023/A:1026534305831.

4. Leprince O, Harren FJM, Buitink J, Alberda M, Hoekstra FA. Metabolic dysfunction and unabated respiration precede the loss of membrane integrity during dehydration of germinating radicles. Plant Physiol. 2000;122:597-608. https://doi.org/10.1104/pp.122.2.597.

5. Glime J. Bryophyte ecology. Volume 1. Physiological ecology. 2006. http:// www.bryoecol.mtu.edu/. 
6. Robinson SA, Tobin AK, Wasley J. Living on the edge — plants and global change in continental and maritime Antarctica. Glob Change Biol. 2003;9(12):1681-717. https://doi.org/10.1046/j.1365-2486.2003.00693.x.

7. Mittler R. Oxidative stress, antioxidants and stress tolerance. Trends Plant Sci. 2004;7(9):407-10. https://doi.org/10.1016/S1360-1385(02)02312-9.

8. Wang X, Chen S, Zhang H, Shi L, Cao F, Guo L, Xie Y, Wang T, Yan X, Dai $S$. Desiccation tolerance mechanism in resurrection fern-ally Selaginella tamariscina revealed by physiological and proteomic analysis. J Proteome Res. 2010:9:6561-77.

9. Blöchl A, Grenier-de March G, Sourdioux M, Peterbauer T, Richter A. Induction of raffinose oligosaccharide biosynthesis by abscisic acid in somatic embryos of alfafa (Medicago sativa L.). Plant Sci. 2005;168(4):1075-82. https://doi.org/10.1016/j.plantsci.2004.12.004.

10. Shinde S, Nurullslam M, Ng CK. Dehydration stress- induced oscillations in LEA protein transcripts involves abscisic acid in the moss, Physcomitrella patens. New Phytol. 2012;195(2):321-8. https://doi.org/10.111 1/j.1469-8137.2012.04193.x.

11. Burla B, Pfrunder S, Nagy R, Francisco RM, Lee Y, Martinoia E. Vacuolar transport of abscisic acid glucosyl ester is mediated by ATP-binding cassette and proton-antiport mechanisms in Arabidopsis. Plant Physiol. 2013;163(3):1446-58. https://doi.org/10.1104/pp.113.222547.

12. Guerrero F, Mullet JE. Increased abscisic acid biosynthesis during plant dehydration requires transcription. Plant Physiol. 1986;80(2):588-91. https ://doi.org/10.1104/pp.80.2.588.

13. Khandelwal A, Cho SH, Marella H, Sakata Y, Perroud PF, Pan A, Quatrano RS. Role of ABA and ABI3 in desiccation tolerance. Science. 2010;327:546.

14. Li H, Wang Y, Wu M, Li L, Li C, Han Z, Yuan Y, Cheng C, Song W, Wang C. Genome-wide identification of AP2/ERF Transcription factors in cauliflower and expression profiling of the ERF family under salt and drought stresses. Front Plant Sci. 2017;8:946. https://doi.org/10.3389/ fpls.2017.00946.

15. Beckett R, Csintalan Z, Tuba Z. ABA treatment increases both the desiccation tolerance of photosynthesis, and nonphotchemical quenching in the moss Atrichum undulatum. Plant Ecol. 2000;151:65-71. https://doi. org/10.1023/A:1026546707649.

16. Nagao M, Minami A, Arakawa K, Fujikawa S, Takezawa D. Rapid degradation of starch in chloroplast and concomitant accumulation of soluble sugars associated with ABA-induced freezing tolerance in the moss Physcomitrella patens. J Plant Physiol. 2005;162(2):169-80. https://doi. org/10.1016/j.jplph.2004.06012.

17. Bartoli CG, Gomez F, Gergoff G, Guiamét JJ, Puntarulo S. Up-regulation of the mitochondrial alternative oxidase pathway enhances photosynthetic electron transport under drought conditions. J Exp Bot. 2005;56(415):1269-76. https://doi.org/10.1093/jxb/eri111.

18. Galmes J, Ribas-Carbo M, Medrano H, Flexas J. Response of leaf respiration to water stress in Mediterranean species with different growth forms. J Arid Environ. 2007;68(2):206-22. https://doi.org/10.1016/j.jarid env.2006.05.005.

19. Murchie EH, Larson T. Chlorophyll fluorescence analysis: a guide to good practice and understanding some new applications. J Exp Bot. 2013;64(13):3983-98. https://doi.org/10.1093/jxb/ert208.

20. Tuba Z, Lichtenthaler HK. Ecophysiology of homoiochlorophyllous and poikilochlorophyllous desiccation-tolerant plants and vegetations. In: Luttge U, Beck E, Bartels D, editors. Plant desiccation tolerance, ecological studies, vol. 215. Heidelberg: Springer; 2011. p. 157-83.

21. Lichtenthaler HK, Wellbur AR. Determination of total carotenoids and chlorophyll a and b of leaf extracts in different solvents. Biochem Soc Trans. 1983;11(5):591-2. https://doi.org/10.1042/bst0110591.

22. Latowski D, Kuczynska P, Strzalka K. Xanthophyll cycle a mechanism protecting plants against oxidative stress. Redox Rep. 2011;16(2):78-90. https://doi.org/10.1179/174329211X13020951739938.

23. Parvaiz A, Cheruth AJ, Mohamed A, Gowher N, Satyawati S. Role of enzymatic and no enzymatic antioxidants in plants during abiotic stress. Rev Biotechnol. 2010;30(3):161-5. https://doi.org/10.3109/073885509035242 43.

24. Cruz de Carvalho R, Catalá M, Branquinho C, Marques da Silva J, Barreno E. Dehydration rate determines the degree of membrane damage and desiccation tolerance in bryophytes. Physiologia Plantarum. 2017;159:277-89.
25. Hu R, Xiao L, Bao F, Li X, He Y. Dehydration-responsive features of Atrichum undulatum. J Plant Res. 2016;129:945-54. https://doi.org/10.1007/s1026 5-016-0836-x

26. Gao B, Zhang D, Li X, Zhang D, Yang H, Liang Y, Chen M, Zhang Y, Zhang J, Wood A. Desiccation tolerance in bryophytes: the rehydration proteomes of Bryum argenteum provide insights into the resuscitation mechanism. J Arid Land. 2018;10(1):152-67. https://doi.org/10.1007/s40333-017-033-3.

27. Vicré M, Farrant JM, Driouich A. Insights into the cellular mechanisms of desiccation tolerance among angiosperm resurrection plant species. Plant Cell Environ. 2004;27(11):1329-40. https://doi.org/10.111 1/j.1365-3040.2004.01212.x.

28. Ashraf $M$, Foolad MR. Roles of glycine betaine and proline in improving plant Abiotic stress resistance. Environ Exp Bot. 2007:59(2):206-16. https ://doi.org/10.1016/j.envexpbot.2005.12.006.

29. Hayat S, Yadav S, Wani AS, Irfan M, Alyemini MN, Ahmad A. Impact of sodium nitroprusside on nitrate reductase, proline and antioxidant system in Solanum lycopersicum under salinity stress. Hortic Environ Biotechnol. 2012;53(5):362-7. https://doi.org/10.1007/s13580-012-0481-9.

30. Makela P, Karkkainen J, Somersalo S. Effect of glycine betaine on chloroplast ultrastructure, chlorophyll and protein content, and RUBPCO activity in tomato grown under drought or salinity. Biol Plant. 2000;43(1):471-5. https://doi.org/10.1023/A:1026712426180.

31. Hara M. The multifunctionality of dehydrins: an overview. Plant Signal Behav. 2010;5(5):503-8. https://doi.org/10.4161/psb.11085.

32. Gao B, Li X, Zhang D, Liang Y, Yang H, Chen M, Zhang Y, Zhang J, Wood A. Desiccation tolerance in bryophytes: the dehydration and rehydration transcriptomes in the desiccation-tolerant bryophyte Bryum argenteum. Sci Rep. 2017;7:757. https://doi.org/10.1038/s41598-017-017-07297-3.

33. Cui S, Hu J, Guo S, Wang J, Cheng Y, Dang X, Wu L, He Y. Proteome analysis of Physcomitrella patens exposed to progressive dehydration and rehydration. J Exp Bot. 2012;63:711-26. https://doi.org/10.1093/jxb/err296.

34. Ashton N, Cove D. The isolation and preliminary characterization of auxotrophic and analogue resistant mutants in the moss Physcomitrella patens. Mol Gen Genet. 1977;154(1):87-95. https://doi.org/10.1007/BF002 65581.

35. Stark L. Ecology of desiccation tolerance in bryophytes: a conceptual framework and methodology. Bryologist. 2017;120(2):130-65. https://doi. org/10.1639/0007-2745-120.2.130.

36. Cruz de Carvalho R, Branquinho C, Marques da Silva J. Physiological consequences of desiccation in the aquatic bryophyte Fontinalis antipyretica. Planta. 2011;243:195-205.

37. Deltoro VI, Calatayud A, Gimeno C, Abadía A, Barreno E. Changes in chlorophyll a fluorescence, photosynthetic $\mathrm{CO}_{2}$ assimilation and xanthophylls cycle interconversions during dehydration in desiccation-tolerant and intolerant liverworts. Planta. 1998;207:224-8.

38. Ross C, Puglisi MP, Paul VJ. Antifungal defenses of seagrasses from the India River Lagoon, Florida. Aquat Bot. 2008;88(1):134-41. https://doi. org/10.1016/j.aquabot.2007.09.003.

39. Beyer WF, Fridovitch I. Assaying for superoxide dismutase activity: some large consequences of minor changes in conditions. Anal Biochem. 1987;161 (87):559-66. https://doi.org/10.1016/0003-2697(87)90489-1.

40. Ederli L, Reale LM, Ferranti F, Pasqualini S. Response induced by high concentration of cadmium in Phragmites australis roots. Physiol Plant. 2004;121(1):66-74. https://doi.org/10.1111/j.00319317.2004.00295.x.

41. Bradford MM. Rapid and sensitive method for the quantitation of microgram quantities of protein utilizing the principle of protein-dye binding. Anal Biochem. 1976;72(1):248-54. https://doi.org/10.1016/00032697(76)90527-3.

42. Lima ALS, DaMatta FM, Pinheiro HA, Totola MR, Loureiro ME. Photochemical responses and oxidative stress in two clones of Coffea canephora under water deficit conditions. Environ Exp Bot. 2002;47:239-47.

43. Costa H, Susana MG, Maria LT. Effect of UV-B radiation on antioxidant defense system in sunflower cotyledons. Plant Sci. 2002;162:939-45. https://doi.org/10.1016/S0168-9452(02)00051-1.

\section{Publisher's Note}

Springer Nature remains neutral with regard to jurisdictional claims in published maps and institutional affiliations. 